\title{
A new Editor-in-Chief for the Journal
}

\author{
Bronwyn Jones
}

Published online: 18 February 2011

(C) Springer Science+Business Media, LLC 2011

The twenty-sixth volume of the Journal ushers in a change in leadership and welcomes a new Editor-in-Chief. Having served the Journal as Editor-in-Chief for 20 years, I am stepping into an emeritus position, although I hope to continue to serve as a reviewer when invited.

The incoming Editor-in-Chief is Reza Shaker, M.D. Dr. Shaker is well known to many of the readership of Dysphagia. He is a Professor of Medicine, Radiology, and Otolaryngology, Chief of the Division of Gastroenterology and Hepatology, Director of the Digestive Disease Center and Senior Associate Dean and Director of the Clinical and Translational Science Institute at the Medical College of Wisconsin-Milwaukee, WI. Dr. Shaker is an internationally recognized gastroenterologist and investigator in the field of dysphagia, gastroesophageal reflux disease and cerebral cortical control of gastrointestinal sensory motor function. His research has led to some of the seminal discoveries in the area of airway protection and has opened new avenues of investigation and treatments for patients with swallowing disorders. He was the first to describe that the deglutitive upper esophageal sphincter opening can be increased by strengthening exercises of the suprahyoid muscles. This led to development of rehabilitative exercises for upper esophageal sphincter dysphagia: the Shaker Exercise. His work has led to the description of the subliminal domain of gut sensory function, allowing investigation of brain-gut axis without the influence of cognitive processes in humans. He developed the field of functional interaction between the upper gut and aerodigestive tract that has resulted in discovery of several related reflexes.

B. Jones $(\bowtie)$

Department of Radiology, The John Hopkins Hospital, 600 N. Wolfe Street, Baltimore, MD 21287, USA

e-mail: bjones1@jhmi.edu

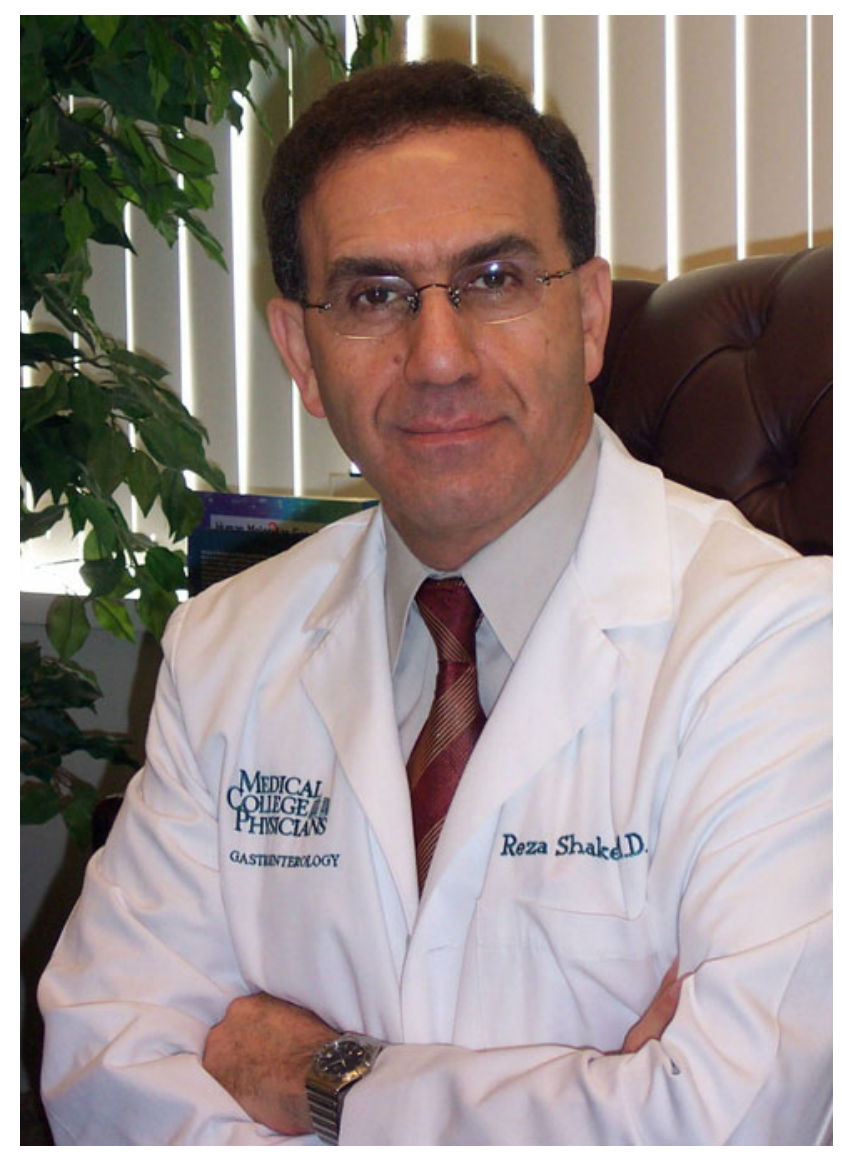

Dr. Shaker has developed the technique of transnasal unsedated upper GI endoscopy for concurrent evaluation of the aerodigestive and upper GI tracts. He is the founder of the Dysphagia Research Society and the Medical College of Wisconsin's Dysphagia Institute.

Although I am somewhat conflicted and saddened to be leaving this position, I am pleased that I will hand over the 
reins to a respected and trusted colleague, and friend. I wish him well in his new endeavor and offer my guidance if required.

I would like to take this opportunity to thank the Associate Editors and Members of the Editorial Board for their support over the years. I would also like to thank all the authors with whom I have interacted (mostly in a positive fashion) for their contributions. My deep thanks to the careful, thoughtful reviewers. Lastly, and by no means least, thank you to the readership. Without your participation, there would be no Journal.

Thank you all for the opportunity to serve as your Editor-in-Chief. Best wishes and good luck to the incoming Editor-in-Chief, Dr. Reza Shaker!

Bronwyn Jones M.D. 